\title{
Desafios da pesquisa em comunicação com o foco na criança e no adolescente no Brasil
}

\author{
Inês Vitorino Sampaio*
}

\begin{abstract}
RESUMO
$O$ artigo discute algumas das conquistas e dificuldades da pesquisa em comunicação no Brasil, com o foco na criança e no adolescente, nas últimas décadas. Ele considera o avanço recente das investigações nesta área e a necessidade de que os desafios da interdisciplinaridade, da abrangência e da complexidade deste campo de investigação, das transformaçōes da concepção de infância e dos cuidados metodológicos na pesquisa com crianças e adolescentes sejam devidamente enfrentados.
\end{abstract}

Palavras-chave: esquisa, comunicação, criança, adolescente

\section{ABSTRACT}

This article discusses some issues of communication research in Brazil that focuses on child and adolescent in the last decades. It considers the recent advance of the inquiries in this area and that the challenges of interdisciplinarity, the complexity of this field, the changes of childhood concept and the methodological cares in the research with children and adolescent need to be faced squarely.

Key words: research, communication, chil, adolescent 
As considerações formuladas neste artigo têm a marca de uma vivência particular como professora e pesquisadora apaixonada pelas questões da infância no campo das ciências sociais e da comunicação, traduzindo algumas das muitas inquietações surgidas no processo de pesquisa e orientação de trabalhos relacionados a este eixo temático. Expressam a conviç̧ão particular da relevância dessa área de pesquisa que envolve as crianças, os adolescentes e a comunicação e ressaltam alguns desafios da investigação neste campo.

Nesse sentido, ainda que represente um esforço de construir um olhar abrangente sobre essa área, não se propõe a apresentar um panorama exaustivo do conjunto das pesquisas em comunicação com este foco no Brasil. Trata-se de uma leitura que, motivada por uma prática de pesquisa e situada em um contexto sócio-cultural especifico, dialoga com os postulados teórico-metodológicos estabelecidos e/ou em processos de desconstrução nesta área.

Buscamos elencar e discutir alguns desafios a serem enfrentados pela pesquisa nesta área, alguns dos quais já vêm sendo discutidos no Brasil, com implicações muito positivas na produção do conhecimento neste campo. São eles os desafios relativos à interdisciplinaridade; à complexidade e à abrangência da problemática investigada; relacionados ao processo de transformação da infância na contemporaneidade e à necessidade de redefinição dos paradigmas do seu entendimento, e, 52 finalmente, atinentes às questões metodológicas referentes à prática de pesquisa com crianças.

\section{O desafio da interdisciplinaridade}

Cremos não haver muita dificuldade na aceitação genérica da tese de que o campo da pesquisa envolvendo a teia de relações da criança e do adolescente com a comunicação apresenta a exigência de uma abordagem interdisciplinar. Trata-se, em primeiro lugar, de uma questão histórica. $\dot{E}$ importante reconhecermos a contribuição de outras disciplinas que antecederam a comunicação no estudo específico das questões da infância, demarcando alguns dos pilares a partir dos quais a problemática da infância e da adolescência pode ser compreendida, como é o caso da própria história, da antropologia, da psicologia, da pedagogia, entre outros.

Em segundo lugar, tal exigência de incursão em outros domínios do conhecimento constitui uma necessidade decorrente da própria natureza do objeto de estudo em questão. Uma compreensão adequada da comunicação midiática, que envolve tanto as representaçzes quanto as distintas formas de interlocução com crianças e adolescentes, remete ao entendimento da natureza complexa dos sujeitos envolvidos neste processo e seus contextos sócio históricos especificos. 
A constituição de uma perspectiva de estudos interdisciplinar implica, assim, um processo permanente de redefinição de saberes e práticas no âmbito das diversas disciplinas, o que exige abertura teórica e rigor metodológico para enfrentá-lo, em um território cuja legitimidade se torna objeto sistemático de disputas. Consideremos, nesse sentido, algumas contribuições fundamentais na área de humanas que precisam ser resgatadas (1).

Com a história, a sociologia e a antropologia aprendemos a reconhecer a infância como arlefato social, desnaturalizado, socialmente construido e, por isso mesmo, dotado de um caráter dinâmico, mutante e diversificado. Em seu clássico 'História Social da Infância e da Família', Ariès (1981) nos incursiona na descoberta da infância e dos sentimentos correlatos a essa identificação, recuperando o processo mediante o qual a sociedade ocidental progressivamente reconhece a peculiaridade deste grupo etário. No Brasil, esse eixo investigativo, retomado, especialmente, por Del Priore (1999) aprofunda as contradições constitutivas das múltiplas vivências da infância, associadas a aspectos referentes à origem de classe, à etnia etc. Na história brasileira, segundo a autora, são muitos os registros das enormes disparidades entre as vidas de uma criança da nobreza e um grumet, um filho de escravo ou de senhor, de 'boa familia' ou bastardo etc. Distorções que ainda hoje permanecem amplamente disseminadas na sociedade brasileira, colaborando para a composição de não apensas uma, mas diversas infâncias.

Com a psicologia do desenvolvimento, em especial com Piaget (1975), a ênfase nos estudos sobre a infância recaiu sobre os processos relativos ao crescimento infantil, possibilitando uma demarcação mais clara da peculiaridade da infância, em seus aspectos cognitivo-afetivo $\mathrm{e}$ sensório motor. Trata-se de uma enorme conquista, à medida que se amplia a compreensão do processo de desenvolvimento infantil e o reconhecimento de que a criança não é apenas um adulto em miniatura.

No campo específico da comunicação, o entendimento de como se realiza o processo de aprendizado da criança, a partir das matrizes oferecidas por Piaget (1975) e Vigotsky (1984) abre novas possibilidades de investigação, constituindo-se, do nosso ponto de vista, condição sine qua non para se discutir os processos de recepção da comunicação midiática por crianças e adolescentes.

Não podemos nos furtar, contudo, de identificar alguns problemas que, não sendo originários da psicologia, encontram em suas formulaçð̃es amplo respaldo. A ênfase em uma leitura ordenadora e disciplinadora dos estágios de evolução infantil tem favorecido e legitimado um processo crescente de tutela da criança, expresso nos processos de escolarização, nas leis, nas políticas públicas de atendimento à criança e ao adolescente etc. A perspectiva disciplinar do controle, tal como entendida por Foucault 
(1979), realizada sob a suposta necessidade de que a criança e o adolescente sejam tutelados, em razão de sua condição de 'ser em formação', possibilita, muitas vezes, o exercício do arbítrio em relação às suas vontades e interesses por parte dos adultos que os cercam. No Brasil, esta é uma discussão que vem sendo enfrentada nos próprios domínios da psicologia, especialmente por Castro (1998), Krammer (1996) e Souza (2000).

No campo da literatura, os belissimos textos de Graciliano Ramos e Cora Coralina atestam, a partir de suas próprias experiências de vida, as duras implicações do poder disciplinar.

"O lugar de estudo era isso. Os alunos se imobilizavam nos bancos: cinco horas de suplício, uma cruxificação. Certo dia vi moscas na cara de um, roendo o canto do olho. E'o olho sem se mexer, como se o menino estivesse morto. Nao há prisão pior que uma escola primária no interior. A imoblilidade e a insensibilidade me aterraram. Abandonei os cadernos e as auréolas, não deixei que as moscas me comessem" (2). (Ramos, 1995: 188)

"Quanto mais enérgicos e ríspidos os pais, maior soma de elogios e gabos captavam, avantajados na aura dos louvores. €Essa senhora sabe criar os filhos.... Isto se dizia quando da notícia de uma tunda de taca, dessas de precisar panos piedosos de saumoura, corretivos de faltas infantis de que a criança não tinha consciência. Humilhação maior, domínio sobre a criança, esta era não raro amarrada com fio de linha na perna da mesa, o sadismo, sobretudo, da mãe. Não amarravam o menino traquinas, levado, dobravam a personalidade da criança." (3). (Coralina, 2001: 103)

Discutir, pois, as questões da comunicação na perspectiva da criança e do adolescente significa partir do reconhecimento dessas contribuições a fim de construir uma visão integrada dos condicionamentos biológico e sócio-histórico que permeiam o processo permanente de definição e redefinição desses grupos etários. Voltaremos a esta questão mais adiante. Consideremos, ainda, alguns aspectos importantes referentes ao campo comunicacional.

\section{O desafio referente à abrangência e à complexidade da problemática investigada}

Se o reconhecimento do desafio interdisciplinar já expressa uma compreensão do caráter complexo dessa área de investigação, é importante reconhecermos que os elementos da abrangência e da complexidade se colocam, também, internamente ao nivel do próprio campo da comunicação. 
Nessa perspectiva, é importante reconhecermos a ampliação expressiva dos interesses temáticos de investigação, especialmente nas últimas décadas, alargando o espectro inicial dos estudos nesta área, cujo foco recaía, quase sempre, nas questões do sexo e da violência nas mídias. Mesmo reconhecendo a recorrência desse tipo de abordagem nos estudos comunicacionais recentes, identificamos como positiva a tendência no sentido de uma maior diversificação nas vertentes de pesquisa e a abertura a um conjunto mais amplo de questões, como discutiremos a seguir.

Neste contexto de alargamento das questões tematizadas nesta área, as novas configurações das esferas públicas contemporâneas e as implicações referentes à constituição de esferas comuns de comunicação entre crianças e adultos têm sido objeto particular da atenção de pesquisadores como Capparelli (2002) e Sampaio $(2000,2003 a)$. No trabalho desses autores, destaca-se a preocupação com as implicações da ampliação do acesso à informação que leva a um processo de redefinição do próprio conceito de infância. Discutem-se a instituição de novas possibilidades comunicativas entre a criança e o adulto, a definição de novas formas comunicacionais, a constituição de uma nova modalidade da experiência pública e privada de comunicação, entre outros.

A questão da criança que conquista um lugar no campo da política é discutida por Sampaio (2003a) com base na campanha eleitoral à Prefeitura Municipal de Fortaleza na midia televisiva em 2000. A partir da identificação da presença significativa da criança nas campanhas, inclusive na condição de interlocutores no âmbito da esfera pública, a autora analisa a abertura de um lugar para o discurso da criança na política midiática, onde a imagem e o discurso infantis são utilizados para promover a legitimação de políticos e políticas públicas.

A questão da criança e do adolescente como personalidades midiáticas torna-se objeto particular de reflexão de Sampaio $(2002,2003 \mathrm{~b})$. Em que medida o glamour que cerca tais personalidades obscurece o problema do trabalho infantil? Se o lúdico, como postula Huizinga (2001), associa-se à inexistência de qualquer outra finalidade além da própria brincadeira, ainda é possivel falar de ludicidade nas atividades infantis de crianças $\mathrm{e}$ adolescentes que dançam, cantam $\mathrm{e}$ interpretam na publicidade, nos programas de auditório ou nas novelas e seriados?

A questão do trabalho infantil é também analisada por Capparrelli e Longhi (2003) no contexto das novas tecnologias. Os estudiosos defendem a idéia da existência de

"implicações qualitativamente diversas em certos produtos culturais digitais, onde a criança participa do processo de produção. Nesse caso a criança é ator ou trabalhador intelectual, tomando a expressão 'produção cultural infantil' nos dois sentidos, ou seja, feita para as crianças como pelas crianças" (2003:04). 
Uma outra vertente importante das pesquisas tem se concentrado na abordagem das formas de representação da criança e do adolescente nas mídias impressas e eletrônicas, em seus diferentes gêneros (jornalismo, publicidade etc.). Essa tem se constituído em uma rica possibilidade de enfrentar a questão dos padrões hegemônicos difundidos pelas mídias e o processo de geração de exclusð̃es de grupos sociais que fogem a tais padrões. Sampaio $(2000,2003 \mathrm{~b})$ destaca como a publicidade tende a invisibilizar as crianças negras, pobres, portadoras de deficiência etc., enquanto o jornalismo inclina-se, com maior frequência, a associar as imagens de crianças e adolescentes negros e pobres à transgressão e à marginalidade. Retomaremos a questão da cobertura jornalística sobre as questões da infância mais adiante.

Uma outra tendência de pesquisas que se detém nos gêneros ficcionais, guardando uma estreita relação com a problemática do consumo, é a pesquisa acerca das narrativas infantis no campo da comunicação midiática, que tem se detido, preferencialmente, nas abordagens da televisão, do cinema e, mais recentemente, dos videogames. Neste corpo de trabalhos, podem ser destacadas as investigações pioneiras de Pacheco (1985) e Fusari (1985), em suas análises da estrutura narrativa do Pica-pau e as implicações da suposta identificação da criança com modelos de comportamento pouco recomendáveis. Entre as abordagens mais recentes, que tematizam as relaçz̃es entre a comunicação midiática e a esfera do 56 consumo, destacamos as contribuiçðes de Capparelli (1997) e Jobim e Souza (2000).

Os autores discutem o processo mediante o qual, a partir de interesses mercadológicos bem definidos, a criança alcança o status de cliente frente à publicidade, sendo valorizada em sua autonomia como consumidora, em um processo que implica novos modos de ser e viver a infância, que incluem a relação com 0 dinheiro e a composição de identidades relacionadas ao consumo, em um processo de definição e redefinição permanente de pertencimentos e exclusões: 'Assim, numa eterna sucessão de filmes, personagens e bens materiais, a criança vai definindo sua identidade de consumidora' (Jobim e Souza, 2000: 107).

Situada neste campo mais abrangente de reflexões, a questão mais específica das estruturas narrativas nos jogos eletrônicos tem sido objeto especial da análise de Cabral (4), que, considerando o caráter de mercadoria dos jogos, que já ocupam o segundo lugar em faturamento no mercado do entretenimento, discute as implicações da associação da violência ao prazer no processo de aprendizado de crianças e adolescentes em sua relação 'interativa' com parcela expressiva dos jogos.

No plano dos direitos da infância, merece menção a ampla pesquisa que vem sendo desenvolvida pela ANDI, sobre o modo como as questões da infância e da adolescência vêm sendo tematizadas na mídia, em especial 
no campo do jornalismo(5). A partir desse propósito, a tese do agendamento é revisitada, permitindo uma reflexão crítica acerca do processo mediante 0 qual as instituições de comunicação pautam determinadas questōes e as conformam de acordo com seus próprios critérios e interesses. Em uma análise crítica desse processo, Godoi (2004) reconhece os avanços na imprensa brasileira, ao incluir a pauta da criança e da adolescência em sua cobertura cotidiana, destacando, contudo, alguns problemas importantes a serem avaliados. Ao considerar as análises especiais desenvolvidas pela ANDI, o autor postula que ainda há relutância no reconhecimento das crianças e dos adolescentes como sujeitos de direitos, dificuldades em efetuar uma cobertura adequada de causas, soluç̃es e consequiências, assim como de assegurar a pluralidade de opiniões.

No plano dos estudos de recepção, as diferentes leituras da criança e do adolescente, em relação às mídias e aos diversos gêneros da comunicação, foram objeto da atenção cuidadosa de Gomes e Cogo (1998), tendo sido enfrentadas, mais recentemente, por vários estudiosos, como Sodré, Paiva, Bucci, entre outros, em uma pesquisa da ANDI, publicada com o sugestivo nome de "Remoto Controle". No primeiro estudo, cuja contribuição já se dá pela escolha do foco nos adolescentes, ainda pouco estudados, Gomes e Cogo (1998) nos remetem a problemáticas, que permanecem bastante atuais, entre as quais se incluem as de natureza mais tópica, como a relação dos adolescentes com os 'supertemas'(6) do sexo e da violência, e outras de natureza mais abrangente referente à multiplicidade de mediaçães no processo comunicacional em que estes sujeitos estão envolvidos.

A pesquisa da ANDl, por sua vez, ao abraçar o desafio de investigar a linguagem, o conteúdo e a participação em 10 (dez) programas de televisão para os adolescentes, sob a ótica deles, além de trazer várias contribuições no sentido de identificar o perfil e os hábitos de consumo de mídia desse grupo etário, colabora para o entendimento de que os adolescentes podem ser críticos em relação às comunicações midiáticas, condenando 'a violência exagerada e individualizada, apresentada em vários programas', a 'fixação em um determinado padrão de beleza física'; identificando 'uma forte distância entre o mundo real e aquele retratado nos programas que thes são dirigidos' etc. (2004: 253).

Uma outra perspectiva importante a ser considerada é a da Educomunicação, com a qual se relacionam muitas das discussões anteriormente elencadas. Soares (1999), em especial, mediante ações articuladas no campo da pesquisa e da extensão, tem trazido uma contribuição fundamental no sentido de identificar este novo campo de convergência de teorias e práticas sociais referentes ao processo de educação para a mídia, em suas vertentes voltadas a 'apropriação dos meios' e de 
'leitura crítica da mídia'. Resgatando como uma de suas matrizes o pensamento de Freire (1981), Soares (1999) e Fischer (2001), entre outros, propõem uma novo referencial para a relação educador-educando, que valoriza a participação infantil no contexto escolar, em um novo processo interativo em que $o$ aluno e o professor aprendem e ensinam um ao outro.

Não podemos, portanto, deixar de reconhecer a ampliação do espectro de questões em debate neste campo investigativo, o que, por um lado, constitui uma expressão da sua complexidade e, por outro, implica o desafio de que as pesquisas considerem, de modo mais efetivo, as articulações entre as questões acima elencadas.

Um último aspecto fundamental quanto a isso é a importância de se reconhecer e enfrentar teórica e metodologicamente a questão da pluralidade de contextos sócio-culturais de vivência da infância, o que remete à consideração de aspectos referentes não só a questão local-global, mas à diversidade cultural no âmbito da própria sociedade brasileira, cuja magnitude coloca desafios da ordem do entendimento das peculiaridades regionais, pouco exploradas ainda nas abordagens da infância e do adolescente em relação à mídia. Para tanto, consideramos fundamental o empenho no sentido de garantir uma maior aproximação dos pesquisadores nesta área. Tal aproximação evitaria alguns problemas de generalização indevida, em que se projeta para o país pesquisas feitas nos grandes centros urbanos, especialmente, do eixo centro - sul.

$58 \mathrm{Na}$ nossa compreensão, portanto, houve um salto qualitativo e, mesmo, quantitativo, das pesquisas nas últimas décadas neste campo. Contudo, se verificarmos, a partir do Sistema Lattes, os grupos de pesquisa com o foco na criança e no adolescente na área da Comunicação, ele é infinitamente inferior ao de outras áreas afins, como a Educação, a Psicologia, a Sociologia, entre outros (7). Se considerarmos os grupos identificados a partir da busca do termo Infância, a Psicologia vem representada com 18 Grupos, a Educação com 16, o Serviço Social com 04, a Sociologia e a Comunicação com 02 , seguido por outros grupos com uma representação. No caso da busca a partir do termo Criança, temos a Psicologia com 23 Grupos, a Educação com 15, o Serviço Social com 05 , o Direito com 03, a Sociologia e a História com 02, a Ciência Política, a Antropologia e Comunicação com apenas 01 . No caso da busca a partir do termo Adolescente, não há registro de nenhum grupo na área de Comunicação, observando-se novamente os destaques nas áreas da Psicologia, com 12 Grupos e Serviço Social, com 06, para citarmos os mais expressivos(6).

$\mathrm{Se}$ as pesquisas estão sendo desenvolvidas, o que atestam as referências anteriormente elencadas, as dissertações e teses defendidas nos programas de pós-graduação do país e os trabalhos de conclusão de curso, qual seria, então, o significado dessa articulação limitada em termos de 
grupos de pesquisa? Que passos poderiam ser dados para garantir uma maior articulação entre os pesquisadores neste campo? Como incluir, efetivamente, a agenda de pesquisas relativas à criança e ao adolescente nos espaços nacionais de discussão, como o Intercom e a Compós? Sem avançar nestes aspectos, torna-se mais dificil enfrentar o desafio de assegurar a abrangência e a complexidade nas abordagens relativas à criança e ao adoicscente no campo da comunicação. Nessa perspectiva, uma questão aglutinadora a ser enfrentada pelo conjunto de pesquisadores da área diz respeito às alterações no próprio conceito de infância.

\section{A exigência de considerar o processo de transformação da infância na contemporaneidade e a redefinição de paradigmas do seu entendimento.}

No campo da comunicação, muito do que se tem desenvolvido em termos de pesquisa envolvendo as representações de crianças e adolescentes, a tematização de questões econômicas, sócio-culturais e políticas ligadas a esse grupo etário e a interlocução com estes sujeitos, traz, como vimos, a marca dos conhecimentos gestados sobre a infância nas diversas áreas, en especial, em sua convergência mais recente no sentido de compreender a criança como um 'ser em formação', digno, portanto, de cuidados especiais.

No caso das pesquisas acerca das relações de crianças $e$ adolescentes com a comunicação, elas não só tem traduzido de modo expressivo uma compreensão de 'menorização da infância', na consideração da criança como um ser frágil e indefeso, mas contam com um elemento agravante, ao se aliar historicamente a uma forte desconfiança em relação às mídias, especialmente a televisão e seus riscos.

Os estudos iniciais, na década de 80 , manifestavam o receio em relação às possibilidades de interferência destrutiva dos meios de comunicação, culpabilizados pelos problemas referentes ao crescimento da violência, à difusão de valores próprios ao capitalismo, à geração de alienação, sendo, por isso mesmo, vistos como perniciosos para o desenvolvimento mental e emocional das crianças. Tal perspectiva vem se mantendo como um dos eixos analíticos difundidos nas últimas décadas, marcando, ainda, uma presença importante nos estudos da comunicação. Como postula Gomes (1995), ele se expressa na noção de vilania aplicada à midia, especialmente a televisão, pautada em uma forte dicotomia entre o bem e o mal, e que apresenta uma leitura do público infantil e adolescente como individuos completamente desprotegidos diante das investidas da mídia.

Este eixo vem sendo rediscutido, nas últimas décadas, especialmente, a partir das revisões das teorias da recepção (Hall, 2003; Barbero, 2001; 
Orozco Gomez, 1990), que questionam as noções de apassivamento no processo comunicacional e apontam para a possibilidade de leituras múltiplas efetuadas por individuos e grupos sociais, a partir das mediações às quais estão sujeitos. Gomes (1995), em uma revisão atenta dos estudos dos processos de recepção infantil, questiona a vertente teórica que não reconhece 'as crianças, enquanto atores do processo receptivo', deixando de fora da análise 'os jogos que fazem com a TV'.

Gomes e Cogo, por sua vez, apóiam-se amplamente no conceito de mediação, considerando-a em suas distintas formas: a individual, a situacional, a institucional e a vídeotecnológica, concluindo, a partir de um estudo etnográfico da audiência dos adolescentes, que 'o processo de recepção televisiva deve ser considerado como um conjunto de práticas que produz sentido e não apenas assimila a cultura hegemônica' (1998: 148). Isso ocorre porque os adolescentes pertencem a uma 'comunidade de apropriação', compartilhando com seus grupos de pertença processos de apropriação e re-apropriação continuados (Jacks, 1999).

Neste percurso analítico, podemos identificar uma tendência mais recente no sentido de reconhecer a criança e o adolescente como ativos no processo de comunicação. Em alguma medida, este reconhecimento, presente também nos estudos de educomunicação, constitui a manifestação de uma nova forma de ver e compreender a criança e o adolescente que cresceram em um ambiente midiático repleto de novas possibilidades comunicativas e expressivas.

O novo cenário da comunicação contemporânea, marcado pelo crescimento vertiginoso do acesso às novas tecnologias, ao possibilitar maior liberdade de acesso e interlocução de crianças e adolescentes conectados ao ciberespaco, colabora sensivelmente para a dissolução de fronteiras entre os mundos infantil e adulto (9). O acesso à internet, ao ampliar o universo de referência de crianças e adolescentes, promove uma redefinição das relações hierárquicas entre adultos e crianças, tensionando poderes tutelares amplamente estabelecidos (Capparelli, 2002).

Neste novo contexto, o maior desafio é compreender quem são as crianças e os adolescentes sobre os quais falamos. Há uma percepça clara, na sociedade e entre os pesquisadores, de que as crianças e os adolescentes estão mudando, mas também uma grande incógnita acerca da direção dessas mudanças. Torna-se a cada dia mais difícil identificar o que seria 'próprio', 'adequado', 'pertinente' para a criança e o adolescente. É justamente esta questão que perpassa os debates acerca da qualidade na produção cultural para a criança e a delicada tarefa de definir um sistema de classificação indicativa que possa orientar pais e educadores na relação com a comunicação midiática, incluindo os programas televisivos, a participação nas salas de bate-papo, o acesso aos sites, o contato com os jogos eletrônicos etc.

Acredito que, embora difícil, seja mais honesto, reconhecer a dificul- 
dade de respondermos a contento esta questão de qual é a nossa compreensão da infância hoje. Os discursos que preconizam a autonomia e/ou a necessidade de proteção de crianças e adolescentes apresentam algumas dificuldades importantes. Como tratar o desafio de proteger sem tutelar, especialmente se considerarmos que o Direito legitima amplamente o controle das vontades da criança e do adolescente pela família e adultos por eles responsáveis? A politica da proteção tem, de fato, colaborado para o bemestar fisico e mental das crianças e dos adolescentes ou se manifesta sobretudo como manifestação do poder disciplinar?

Se reconhecemos as políticas e dispositivos de proteção como conquistas importantes da sociedade brasileira, como o é o caso do Estatuto da Criança e do Adolescente (ECA), que completou em julho seus 15 anos, não podemos obscurecer o fato de que existem algumas contradições que permejam os discursos da proteção. De um lado temos a afirmação legítima da criança e do adolescente como sujeitos de direitos e, de outro, a manutenção de uma compreensão da infância a partir das noções de falta, incompletude, fragilidade etc., em que a criança e o adolescente são vistos, sobretudo, como projetos de futuro.

"Assim, a compreensão da especificidade da infância fica por conta de um фdébito social e cultural $\not$ que the é atribuido frente à tarefa de crescer, e se tornar, eventualmente como um adulto. Frente a esse débito, interpõem-se as ações educativas e familiares que visam, então, $\varnothing$ fazer das crianças adultos $\notin, \notin$ socializá-las $\phi$, фamadurecê-las $\varnothing$, enfim, operar sobre a infância com o dever de torná-la sempre evanescente, um traço a ser apagado e destruído, um momento, por principio transitório" (Castro, 2001: 20)

Um outro aspecto importante postulado por Castro (1998) diz respeito às implicaçð̃es no campo teórico das ciências sociais desta tendência de 'menorização da criança e do adolescente'. Nesse processo, é a própria pesquisa no campo da infância que termina por ser considerada 'menor' frente a outras áreas, vistas como mais importantes. Talvez isso explique, em alguma medida, a secundarização das pcsquisas relativas à infância e ao adolescente, frente a outras investigações tidas como 'mais relevantes' na área de comunicação. A pesquisa com o foco na criança e no adolescente não confere status ao pesquisador? É vista como um assunto muito específico e, por isso mesmo, 'menor'?

Um outro aspecto, também associado à compreensão da infância, particularmente no que diz respeito ao reconhecinento das suas especificidades, é a questão metodológica, discutida a seguir. 


\section{O desafio metodológico referente à prática da pesquisa com crianças}

Os pesquisadores que já tiveram a oportunidade de desenvolver projetos diretamente com crianças certamente se depararam com o desafio de definir metodologias e procedimentos de pesquisa capazes de contemplar as peculiaridades infantis, do ponto de vista cognitivo, afetivo e sensóriomotor. Tais especificidades, envolvendo aspectos como a atenção, a concentração, o nível de compreensão e a capacidade expressiva da criança, precisam ser consideradas, sob o risco de, ao se assumir uma postura meramente reprodutiva dos métodos e técnicas utilizadas na abordagem de outros públicos, não se perceber, de fato, a criança.

O desafio que está posto, portanto, é: como ouvir, efetivamente, as vozes infantis e nã̃o apenas as ressonâncias de nossos próprios discursos aduitocêntricos? Na nossa compreensão, é importante reconhecermos que a marca histórica da 'paparicação', tal como discute Ariès (1981), ainda impõe dificuldades para que os discursos de crianças e, em alguns casos, até mesmo de adolescentes sejam levados a sério. Para tanto, é preciso romper com o sentimento de 'paparicação' no processo de pesquisa que, em última instância, opera no sentido da menorização da criança.

Trata-se, em primeiro lugar, de reconhecer um lugar legítimo de interlocução da criança e do adolescente em sua condição de sujeitos do 62 conhecimento, capazes, portanto, de comunicação. Em segundo lugar, trata-se de buscar 'novos mecanismos de comunicação' no processo de pesquisa, que implique uma postura efetiva de redimensionamento dos nossos modos de ver e ouvir a criança. Nessa linha, acreditamos que um ponto de partida importante possa ser o reconhecimento do lúdico como território fértil de desenvolvimento da comunicação entre crianças e adultos no processo de pesquisa, uma abordagem já inaugurada pela psicologia, utilizando recursos como o desenho, o brinquedo, a dramatização etc., com resultados bastante satisfatórios.

\section{Considerações finais}

Este breve resgate das pesquisas em comunicação com o foco na criança e do adolescente no Brasil nas últimas décadas permite-nos identificar o quanto a pesquisa nesta área tem avançado no país, no que se refere à abrangência de suas temáticas e ao refinamento dos seus referenciais teóricos e metodológicos. Há conquistas importantes a serem, pois, valorizadas. Somos forçados, contudo, a reconhecer que a consideração das abordagens relativas à infância vistas como algo muito específico, até mesmo 'menor', como sinalizado anteriormente, colabora para que a produção acadêmica em torno desse eixo investigativo permaneça integrada a línhas de pes- 
quisas mais reconhecidas no interior do campo da comunicação, auferindo, por isso mesmo pouca visibilidade, com implicações importantes do ponto de vista da integração entre os pesquisadores.

Diante dos vários desafios anteriormente discutidos quanto aos aspectos da interdisciplinaridade, da abrangência e complexidade da problemática investigada, do processo de transformação da infância na contemporaneidade e a exigência de redefinição dos paradigmas do seu entendimento, e, por último, das questões metodológicas referentes à prática de pesquisa com crianças, consideramos importante destacar que tais questões só poderão ser devidamente enfrentadas de forma conjunta.

Nessa perspectiva, a questão do entendimento do processo de transformação na infância na contemporaneidade, da compreensão acerca de quem são as crianças e os adolescentes sobre os quais tanto falamos, está posta como desafio aglutinador das mais diversas pesquisas nesse campo. O reconhecimento das nossas próprias limitações em lidar com esta questão da infância hoje, considerando as tensões entre autonomia e proteção, cidadania e consumo, direitos e deveres de criança e adultos, relacionados, em grande medida, a um processo histórico que está em curso, pode significar um passo decisivo para a abertura de novos caminhos investigativos e a superação de antigos impasses.

\section{Referências bibliográficas}

AGÊNCIA DE NOTÍCIAS DOS DIREITOS DA INFÂNCIA. Controle remoto: linguagem, conteúdo e participação nos programas de televisão para adolescentes. Coordenação Veet Vivarta. São Paulo, Cortez, 2004. Série Mídia e Mobilização Social.

ARIĖS, Philippe. História social da criança e da famiilia. Rio de Janeiro, LTC, 1981 .

BASTOS, Laura. A criança diante da TV: um desafio para os pais. Petrópolis, Vozes, 1988.

BENJAMIN, W. Reflexões: A criança, o brinquedo, a educação. São Paulo, Ed. Summus, 1984.

CAPARELLI, Sérgio. Infância digital e cibercultura in Lemos, André e outros (org). Críticas das práticas midiáticas, São Paulo, 2002.

- A Emergência da criança no espaço do consumo in JOBIM e SOUZA, S, e outros (org.) Infância, cinema e sociedade. Rio de Janeiro, Ravil/Escola de Professores, 1997.

CAPPARELLI, Sérgio e LONGHI, Raquel. A produção cultural digital para crianças in Anais do XXVI Congresso Brasileiro de Ciências da Comunicação, Belo Horizonte, 2003.

CASTRO, Lúcia Rabello de ( Org.) Infância e adolescência na cultura de consumo. Rio de Janeiro: Nau, 1998. 
CORALINA, Cora. Vintém de cobre. Meias confissões de Aninha, São Paulo, Global, 2001.

FISHER, Rosa Ma.B. Televisão e educação: fruir e pensar a TV. Belo Horizonte, Ed. Autêntica, 2001.

FREIRE, Paulo. A educação como prática da liberdade. Rio de Janeiro, Paz e Terra, 1981.

FOUCALT, Michel. Microfisica do poder. Rio de Janeiro, Ed. Graal, 1979.

FUSARI, Maria Felisminda de Resende e. $O$ Educador e o desenho animado que a criança vê na televisão. São Paulo, Loyola, 1985.

GODOI, Guilherme Canela de Souza. Jornalismo, agendamento e a construção de uma esfera pública de discussões sobre a infância $e$ adolescnência: a experiência da Agência de Notícias dos Direitos da Infância. $7 \mathrm{mo}$ Congreso Latinoamericano de Investigadores de la Comunicación, La Plata, Buenos Aires, Argentina, 2004.

GOMES, Pedro Gilberto e COGO, Denise Maria. O Adolescente e a televisão. Porto Alegre, Editora da UNISINOS, 1998.

GOMES, Itânia. Ingenuidade e recepção: as relações da criança com a TV in: Rocha Filho, Aristóteles e Outros (Orgs.) O Sentido e a Época: Ensaios sobre a Cultura na Era da Informação, Salvador, 1995.

HUIZINGA, Johan. Homo ludens, São Paulo, Perspectiva, 2001.

HALL, Stuart. Codificação-Decodificação in Da Diáspora: identidades e mediações culturais, Belo Horizonte, UFMG; Braślia, Representação da

64 UNESCO no Brasil, 2003.

JACKS, Nilda. Querência. Identidade cultural como mediação simbólica. Um estudo de recepção. Porto Alegre, Editora da Universidade UFRGS, 1999.

KRAMER, Sônia e LEITE, Isabel (orgs.) Infância e produção cultural. Campinas, SP, Papirus, 1996.

MEYEROWITZ, Joshua. No Sense of Place. New York: Oxford University Press, 1985.

MARTIN-BARBERO, Jésus. Dos meios às mediações: comunicação, cultura e hegemonia, Rio de Janeiro, EDUFRJ, 2001.

OROZCO, Guillermo. El niño como televidente no nace, se hace in CHARLES CREEL, Mercedes \& OROZCO GÓMEZ, Guillermo. Educación para la recepción: hacia una lectura crítica de los medios, México, Trillas, 1990.

PACHECO, Elza D. P. Pica-Pau: Herói ou Vilão? - representação da criança e reprodução da ideologia dominante. São Paulo, Loyola, 1985.

1998.

- Televisão, criança, imaginário e educação. Campinas, Papirus,

PIAGET, Jean. A construção do real na criança. Rio de Janeiro, Zahar, 1975.

PRIORE, Mary de (org). História das crianças no Brasil, São Paulo, Contexto, 1999. 
POSTMAN, N. $O$ desaparecimento da infância. Rio de Janeiro: Graphia Editorial, 1999.

RAMOS, Graciliano. Infância. Rio de Janeiro: Ed. Record, 1985.

REZENDE, Ana Lúcia M. de e REZENDE, Nauro Borges de. A Tevê e a criança que te vê. São Paulo, Cortez, 1989.

SAMPAIO, Inês. Televisão, publicidade e infância. Fortaleza, Secretaria de Cultura e Desporto do Estado do Ceará; São Paulo, Annablume, 2000.

. As Crianças na politica midiática in CARVALHO, Rejane Aciolly

Vasconcelos de. (Org.) A produção da política em campanhas eleitorais: eleições municipais de 2000. Campinas, São Paulo; Fortaleza, Programa de Pós-Graduação em Sociologia da UFC, 2003a.

Imagens da primeira infância na midia, Anais do I Simpósio Ncional "A Primeira Infância na Cultura da Paz", São Paulo, CoPIPAZ, 2003b.

SOARES, Ismar de Oliveira. Comunicação/Educação, a emergência de um novo campo e o perfil de seus profissionais in Contato, Revista Brasileira de Comunicação, Arte e Educação, Brasília, ano 1, n.2, 1999.

SOUZA, Solange Jobim e (org.) Subjetividade em questão. A infância como crítica da cultura. RJ, 7 Letras, 2000.

VIGOTSKY, L.S. A Formação social da mente, São Paulo, Martins Fontes, 1984.

\section{Notas}

1 - O destaque conferido às disciplinas na área de humanas não tem a pretensão de negar outras contribuições fundamentais em outras áreas do conhecimento científico, como é o caso da Medicina ao tematizar os cuidados com a saúde da criança e do adolescente.

2 - Graciliano Ramos nasceu em Alagoas em 1892.

3 - Cora Coralina nasceu em Goias em 1889.

4- Pesquisa apresentada na Sessão $A$ sedução dos Jogos Eletrônicos na 4a. Cúpula Mundial de Mídia para Crianças e Adolescentes, Rio de Janeiro, 2004. 5- Ver sobre isso os 08 (oito) volumes da Série Mídia e Mobilização Social, publicados pela Cortez Editora

6 - Os "supertemas" são para Orozco (apud Gomes e Cogo, 149) "aqueles universos temáticos que são cotidianamente importantes para a audiência". 7 - Disponível em http://lattes.cnpq.br (Acesso em 03.05.2005)

8 -Temos consciência da possivel existência de repetições dos grupos a partir dos diferentes termos de busca, o que não invalida o propósito de selecionálos, a fim de identificar os diversos grupos a partir dos recortes disciplinares especificos.

9- Cf. sobre a tendência dissolução de fronteiras entre o mundo infantil e adulto os trabalhos de Postman (1999) e Meyrowitz (1985). 
